\title{
Menstrual hygiene management among women and adolescent girls in the aftermath of the earthquake in Nepal
}

Shyam Sundar Budhathoki ${ }^{*}$, Meika Bhattachan ${ }^{1}$, Enrique Castro-Sánchez ${ }^{2}$, Reshu Agrawal Sagtani ${ }^{3}$ Rajan Bikram Rayamajhi ${ }^{4}$, Pramila Rai ${ }^{1}$ and Gaurav Sharma ${ }^{5}$

\begin{abstract}
Background: Menstrual hygiene management (MHM) is an essential aspect of hygiene for women and adolescent girls between menarche and menopause. Despite being an important issue concerning women and girls in the menstruating age group MHM is often overlooked in post-disaster responses. Further, there is limited evidence of menstrual hygiene management in humanitarian settings. This study aims to describe the experiences and perceptions of women and adolescent girls on menstrual hygiene management in post-earthquake Nepal.

Methods: A mixed methods study was carried out among the earthquake affected women and adolescent girls in three villages of Sindhupalchowk district of Nepal. Data was collected using a semi-structured questionnaire that captured experiences and perceptions of respondents on menstrual hygiene management in the aftermath of the Nepal earthquake. Quantitative data were triangulated with in-depth interview regarding respondent's personal experiences of menstrual hygiene management.
\end{abstract}

Results: Menstrual hygiene was rated as the sixth highest overall need and perceived as an immediate need by $18.8 \%$ of the respondents. There were $42.8 \%$ women \& girls who menstruated within first week of the earthquake. Reusable sanitary cloth were used by about $66.7 \%$ of the respondents before the earthquake and remained a popular method (76.1\%) post-earthquake. None of the respondents reported receiving menstrual adsorbents as relief materials in the first month following the earthquake. Disposable pads (77.8\%) were preferred by respondents as they were perceived to be clean and convenient to use. Most respondents (73.5\%) felt that reusable sanitary pads were a sustainable choice. Women who were in the age group of $15-34$ years $(\mathrm{OR}=3.14 ; \mathrm{Cl}=(1.07-9.20)$, did not go to school $(\mathrm{OR}=9.68 ; \mathrm{Cl}=2$. 16-43.33), married $(\mathrm{OR}=2.99 ; \mathrm{Cl}=1.22-7.31)$ and previously used reusable sanitary cloth $(\mathrm{OR}=5.82 ; \mathrm{Cl}=2.33-14.55)$ were more likely to use the reusable sanitary cloth.

Conclusions: In the immediate aftermath of the earthquake, women and girls completely depended on the use of locally available resources as adsorbents during menstruation. Immediate relief activities by humanitarian agencies, lacked MHM activities. Understanding the previous practice and using local resources, the reusable sanitary cloth is a way to address the menstrual hygiene needs in the post-disaster situations in Nepal.

Keywords: Menstrual hygiene, Nepal earthquake, Sexual and reproductive health, women's health

\footnotetext{
* Correspondence: ss.budhathoki@gmail.com

${ }^{1}$ School of Public Health \& Community Medicine, B P Koirala Institute of

Health Sciences, Dharan, Nepal

Full list of author information is available at the end of the article
} 


\section{Background}

Menstruation is a naturally occurring physiological phenomenon in adolescent girls and pre-menopausal women [1]. Menstrual Hygiene Management (MHM) is defined as 'Women and adolescent girls using a clean menstrual management material to absorb or collect blood that can be changed in privacy as often as necessary for the duration of the menstruation period, using soap and water for washing the body as required, and having access to facilities to dispose of used menstrual management materials'. Menstruation necessitates the availability of material resources to absorb or collect menstrual blood, facilitate personal hygiene and dispose of waste, ideally with adequate privacy [2]. Women and girls in low income settings have low awareness on hygienic practices and lack culturally appropriate materials for menstrual hygiene management (MHM) practices [3-5]. Menstruation and associated activities are surrounded by silence, shame and social taboos that are further manifested in social practices that restrict mobility, freedom and access to normal activities in India and Nepal. For instance, drinking milk, preparing food, interacting with people or refraining from performing religious rituals are restrictions found in many cultures [5-9].

The materials used as adsorbents during menstruation in low income countries including Nepal, vary from reusable towels (cloth torn from dresses of women and cotton fabric) to commercially available disposable sanitary pads [6, 10-15]. Practical, sustainable and culturally acceptable methods are recommended for addressing the menstrual hygiene needs of women in low income countries $[4,16]$. Types of adsorbents used, hygienic practices and cultural restrictions during menstruation are associated with negative clinical and psychosocial outcomes including reproductive and urinary tract infections, anemia, school absenteeism, and social isolation $[1,6,15,17,18]$.

Young adolescent girls tend to be less prepared for MHM and suffer from anxiety, apprehensions, fear and shame during their menses [12, 19]. In addition, preexisting social taboos and cultural restraints during menstruation mean that managing menstruation is a greater challenge during disasters [20-22]. Further, there is limited access to reproductive health services and safe menstrual hygiene materials during disasters [23]. Menstrual hygiene needs are not only specific and pressing to women and girls in reproductive age but also require access to same management of the menstrual period, a basic reproductive health right. In emergencies, the usual lifestyles of affected individuals change and they are confronted with additional stress that could worsen their physical and psychological well-being. Provision of fundamental human requirements such as shelter, food, clean water and medicines is prioritised, however other needs such as safe menstrual hygiene management that can have profound psychosocial impact if unmet are often neglected [22, 24].

On $25^{\text {th }}$ April 2015, Nepal was affected by a 7.8 Richter scale magnitude earthquake killing almost 9000 people and displaced 3.5 million people [25]. Compared to men, more women survived [26] and although emergency relief and rescue operations swiftly began addressing essential humanitarian needs, there seemed to be a lack of attention to menstrual hygiene needs of adolescent girls and women [13,27]. Although increasingly considered, menstrual hygiene continues to be overlooked during disasters, even in community level responses [22, 28, 29]. Nepal is frequently affected by disasters, both natural as well as manmade leading to displacement of the population into temporary shelters $[25,30]$.

Menstrual hygiene is a need of menstruating women \& girls. Although, there are some studies on menstrual hygiene management in Nepal, there is limited evidence on menstrual hygiene management especially in the aftermath of the earthquake in Nepal [12, 13, 21, 31]. Therefore, we conducted this study to explore the perceptions and the lived experience of women and young girls regarding menstrual hygiene management in the aftermath of the earthquake in Nepal.

\section{Methods}

\section{Study design\& settings}

This study was conducted amongst 117 women and adolescent girls in three villages of Sindhupalchowk district of Nepal. The selected district was chosen since it was one of the most earthquake affected district [26]. The data collection was conducted from 16th August until 29th August 2015.

\section{Sampling strategy and sample size}

We purposely selected Chautara (the main hub of Sindupalchowk district) [32] and 2 other villages adjacent to Chautara (Kubhinde and Pipaldanda) for our study. According to the 2011 census of Sindhupalchowk district, the population of girls and women in the age group of 15-49 years in the study areas was 3484 $($ Chautara $=1759$; Kubhinde $=784 ;$ \& Pipaldanda $=941)$. As the earthquake affected $65 \%$ of the population of the district, the estimated number of women and girls eligible to participate in the study would be 2316 . We planned to interview $5 \%$ of this target population with $10 \%$ amplification for possibility of non-response errors. Thus, the estimated final sample size was 127.

\section{Participants}

A purposive sampling technique was employed to invite 127 women and adolescent girls living in temporary shelters set up in the district to participate in the study. Adolescents who had not had menarche and menopausal 
women were excluded from the study. The interviews were scheduled at the time of the day when there were no relief materials being distributed in the areas and the women and girls were free to participate.

\section{Data collection and analysis}

Quantitative data was collected using a semi-structured questionnaire comprising of socio-demographic characteristics, menstrual practices prior to the earthquake, perceived needs and menstrual hygiene practices during the post-earthquake period and preferred adsorbents for MHM during the aftermath of the earthquake. Face-toface interview conducted by female interviewers are graduate medical and nursing professionals who were given 3-4 h orientation on both quantitative and qualitative questions before the data collection by the research team. The questionnaire was finalised in English and then translated into Nepali before the data collection using the translation-back translation method. The interviews were conducted in Nepali language. Pretesting of the questionnaire was conducted with women and adolescent girls residing in temporary settlement areas of Kathmandu $(n=20)$ to ensure that questions were socio-culturally acceptable and completely answered our research question.

Additionally, qualitative data was collected from a number of respondents $(n=5)$ who had their menses on the day or within the first week of the earthquake. The women and girls were invited to participate in a brief in-depth interview, which lasted for 10-15 min, including open questions on menstruation experience and its management ('Could you share your experience on your first menstruation after the earthquake?' and 'Could you elaborate on the management of your menstruation'). A female interviewer recorded the interview and took field notes. The interview took place in Nepali language. The recording was later transcribed as verbatim.

The quantitative data was initially entered in Microsoft Excel and later analysed using the SPSS Statistics for Windows, Version 21.0. Armonk, NY: IBM Corp. The qualitative material was analysed by the researchers using thematic analysis [33]. An initial thematic framework was developed using a deductive-inductive approach. The framework was refined and used to analyse the remaining interviews. Transcripts were examined line-by-line and coded using thematic analysis. Key categories and themes were identified and iteratively compared within the framework to elicit further emerging codes. Thematic saturation was considered once the analysis of data offered no new information and a redundancy of categories.

\section{Ethical considerations}

Ethical approval for this research was obtained from the Institutional Review Committee of B P Koirala Institute of Health Sciences (Ref: IRC/634/015), Dharan, Nepal.
Prior to the start of the data collection, researchers met with community leaders and outlined the purpose and objectives of the study. The research team were external to the ongoing relief operations and had no influence on their logistics or other conflict of interests. After receiving approval from the community leaders and with the support of the local women's group representative, suitable participants were identified. Literate women were given an information sheet that provided details on the research objectives, expected role of the respondents and the voluntary nature of participation. They were informed that their decision to participate or decline participation would not affect any benefits or services received by them. Written informed consent was obtained from all literate participants. For women unable to read, the information sheet was read out and the research objectives, expected roles of participants and voluntary nature of participation was explained in the presence of a literate female elder. A thumb print was obtained and this was countersigned by another witness. For respondents between 15 and 17 years, an assent form was used along with the permission of a parent/guardian to participate in the study.

\section{Results}

The research team identified 127 eligible individuals, of whom 117 agreed to participate (response rate 92.1\%). Table 1 presents sociodemographic characteristics of the participants. Almost 65\% (77) of the respondents had some schooling, with $10 \%$ (11) attaining a university level education. More than $70 \%$ (84) of respondents were married. About $67 \%$ of respondents reported using a reusable cloth as a sanitary adsorbent during menstruation regularly before the earthquake. More than $80 \%$ (102) of respondents changed adsorbents two or more times daily during menstruation (Table 1).

When respondents were asked to recall up to five immediate needs following the earthquake; food (97\%), shelter (75.2\%), water (63.2\%), clothes (47.0\%) and information about family members/relatives (29.9\%) were the five highest ranked needs. Menstrual hygiene was the sixth highest perceived need, listed by $18.8 \%$ of the respondents (Table 2).

Within the first month of the earthquake, none of the respondents reported having received any menstrual hygiene adsorbents within the distributed relief materials. Soap was received by $50.4 \%$ of women and girls. Availability of a safe space with adequate privacy for changing of adsorbents was reported by $42.7 \%$ of respondents. About $12 \%$ of women perceived the need for adsorbents required for menstrual hygiene management on the same day just after earthquake took place. About $23.9 \%$ of respondents had access to disposable sanitary pads for managing the menstrual bleeding. Of these 28 respondents, $42.8 \%$ had borrowed them either from a relative or friend, 39.3\% 
Table 1 Sociodemographic characteristics of study participants $(n=117)$

\begin{tabular}{ll}
\hline Variables & No (\%) \\
\hline Age & \\
15-24 years & $42(35.9 \%)$ \\
$25-34$ years & $40(34.2 \%)$ \\
$35-49$ years & $35(29.9 \%)$ \\
Education & \\
No formal schooling & $40(34.2 \%)$ \\
Primary School & $6(5.1 \%)$ \\
Secondary School & $60(51.3 \%)$ \\
University & $11(9.4 \%)$ \\
Marital Status & \\
Unmarried & $33(28.2 \%)$ \\
Married & $84(71.8 \%)$ \\
Adsorbents type used before earthquake & \\
Disposable Pads & $39(33.3 \%)$ \\
Reusable Cloth & $78(66.7 \%)$ \\
Frequency of adsorbent changes/day during \\
menstruation before earthquake \\
Once
\end{tabular}

Table $\mathbf{2}$ Immediate post-earthquake needs as perceived by study respondents

\begin{tabular}{ll}
\hline Variables & No (\%) \\
\hline \multicolumn{1}{c}{ Perceived need* } \\
Food & \\
Shelter & $114(97.4 \%)$ \\
Water (Drinking \& Washing) & $88(75.2 \%)$ \\
Clothes & $74(63.2 \%)$ \\
Information about Family Members/relatives & $55(47.0 \%)$ \\
Adsorbents for Menstrual Hygiene & $35(29.9 \%)$ \\
Mobiles & $22(18.8 \%)$ \\
Medicine/First aid & $17(14.5 \%)$ \\
Safe place & $13(11.1 \%)$ \\
Soap & $12(10.3 \%)$ \\
Cattle & $8(6.8 \%)$ \\
\hline
\end{tabular}

*Multiple responses bought from vendors, and $17.9 \%$ used the remaining pads from a previous occasion. Almost $76 \%$ of respondents used reusable cloths for managing menstrual bleeding, made mostly from old clothes (78.7\%). About $85 \%$ of respondents who could use disposable sanitary pads disposed the used pads at a random nearby open and uninhabited space. Majority of respondents (77.8\%) preferred disposable pads as adsorbents, as they were perceived to be cleaner, more hygienic, easier to use and more comfortable than alternative options. For those respondents who preferred reusable cloth as adsorbents (22.2\%), easy availability, reusability, and habit were the reported reasons (Table 3).

Age, education, marital status and the type of adsorbents used before were associated with the type of adsorbents used during the menstruation immediately after the earthquake. In post-earthquake situation, women who are in the age group of 15-34 years used reusable sanitary cloth 3 times more $(\mathrm{OR}=3.14 ; \mathrm{CI}=(1.07-9.20)$ than the girls in the age group of 15-24 years. Women \& girls who had no school education used reusable sanitary cloth 9 times more $(\mathrm{OR}=9.68 ; \mathrm{CI}=2.16-43.33)$ than those who had some school education. Married women \& girls used reusable sanitary cloth 3 times more $(\mathrm{OR}=2.99$; $\mathrm{CI}=1.22-7.31)$ than those who were unmarried. Women \& girls who used reusable sanitary cloth prior to earthquake used reusable sanitary cloth 5 times more $(\mathrm{OR}=5.82 ; \mathrm{CI}=2.33-14.55)$ than those who used disposable pads prior to the earthquake (Table 4).

\section{Qualitative findings}

Experience of managing first menstrual period immediately after the earthquake was explored using qualitative technique. The in-depth interviews were coded into the three themes, 1. Experiences of women in accessing adsorbents, 2. Personal hygiene related issues and 3. Finding safe space during the first menstrual period. Five women described in short in-depth interviews their experience of managing their first menstrual period after the earthquake. Even during a desperate situation such as the event faced by the respondents, menstrual hygiene management was still seen as a private issue. This belief also extended to where they went for help. As a collectivistic society [34], it was still possible for women to share problems with friends and get some help when available.

\section{Experiences of women in accessing adsorbents} The respondents said:

"...sanitary pads did not strike my mind until four days after the earthquake during afternoon when my periods began. My brother asked me if there was a problem as I was staying inside for a long time. I just couldn't say out loud that I started my periods. I stayed inside the tent until 
Table 3 Menstrual Hygiene Management-related responses related to first month post-earthquake $(n=117)$

\begin{tabular}{|c|c|}
\hline Variables & $n(\%)$ \\
\hline \multicolumn{2}{|l|}{ Received adsorbents as relief material } \\
\hline Did not receive & $117(100.0 \%)$ \\
\hline \multicolumn{2}{|l|}{ Receive soap as relief material } \\
\hline Did not receive & $59(50.4 \%)$ \\
\hline Received as relief material & $58(49.6 \%)$ \\
\hline \multicolumn{2}{|l|}{ Privacy available for MHM practice } \\
\hline Not adequately available & $67(57.3 \%)$ \\
\hline Adequately available & $50(42.7 \%)$ \\
\hline \multicolumn{2}{|c|}{ Timing to remember adsorbents as a need } \\
\hline On the day of earthquake & $15(12.8 \%)$ \\
\hline Only when menstruation occurred & $102(87.2 \%)$ \\
\hline \multicolumn{2}{|c|}{ Type of adsorbents used after the earthquake } \\
\hline Disposable Pads & $28(23.9 \%)$ \\
\hline Reusable Cloth & $89(76.1 \%)$ \\
\hline \multicolumn{2}{|c|}{ Source of the adsorbents? (Disposable pads; $n=28$ ) } \\
\hline Relative or Friend & $12(42.8 \%)$ \\
\hline Bought & $11(39.3 \%)$ \\
\hline Remaining from last time & $5(17.9 \%)$ \\
\hline \multicolumn{2}{|c|}{ Source of the adsorbents? (Reusable cloths; $n=89$ ) } \\
\hline Old clothes & $70(78.7 \%)$ \\
\hline Relative or Friend & $19(21.3 \%)$ \\
\hline \multicolumn{2}{|c|}{ Disposal site for used disposable pad $(n=28)$} \\
\hline Along with other waste & $4(14.3 \%)$ \\
\hline Separately in a nearby open space & $24(85.7 \%)$ \\
\hline \multicolumn{2}{|l|}{ Preferred choice of adsorbents } \\
\hline Disposable Pads & $91(77.8 \%)$ \\
\hline Reusable Cloth & $26(22.2 \%)$ \\
\hline \multicolumn{2}{|c|}{ Reason for preferring Disposable pads $(n=91)$} \\
\hline Clean & $47(40.2 \%)$ \\
\hline Hygienic & $18(19.8 \%)$ \\
\hline Easy to use & $15(16.5 \%)$ \\
\hline Comfortable & $11(12.1 \%)$ \\
\hline \multicolumn{2}{|c|}{ Reason for preferring Reusable cloth $(n=26)$} \\
\hline Easy availability & $14(53.8 \%)$ \\
\hline Reusability & $10(38.5 \%)$ \\
\hline Habit & $2(7.7 \%)$ \\
\hline \multicolumn{2}{|l|}{ Perceived sustainable choice in disasters } \\
\hline Disposable Pads & $31(26.5 \%)$ \\
\hline Reusable Cloth & 86 (73.5\%) \\
\hline
\end{tabular}

dark and then I started asking my close friends and I got some disposable pads, which I promised to return in a few days." (15-19 years; high school graduate; respondent ID 1)
Table 4 Factors affecting the use of adsorbents in immediate post-earthquake Nepal

\begin{tabular}{|c|c|c|c|c|}
\hline \multirow[t]{2}{*}{ Variables } & \multicolumn{2}{|c|}{$\begin{array}{l}\text { Type of Adsorbents used } \\
\text { after earthquake }\end{array}$} & \multirow[t]{2}{*}{$\begin{array}{l}\text { Unadjusted } \\
\text { OR (95\% Cl) }\end{array}$} & \multirow[t]{2}{*}{$p$-value } \\
\hline & Reusable Cloth (\%) & Disposable Pads (\%) & & \\
\hline \multicolumn{5}{|l|}{ Age } \\
\hline $15-24$ years & $27(64.3)$ & $15(35.7)$ & 1 & \\
\hline $25-34$ years & $34(85.0)$ & $6(15.0)$ & $\begin{array}{l}3.14 \\
(1.07-9.20)\end{array}$ & 0.031 \\
\hline $35-45$ years & $28(80.0)$ & $7(20.0)$ & $\begin{array}{l}2.22 \\
(0.78-6.29)\end{array}$ & 0.128 \\
\hline \multicolumn{5}{|l|}{ Education } \\
\hline School education & $51(66.2)$ & $26(33.8)$ & 1 & .000 \\
\hline $\begin{array}{l}\text { No School } \\
\text { Education }\end{array}$ & $38(95.0)$ & $2(5.0)$ & $\begin{array}{l}9.68 \\
(2.16-43.33)\end{array}$ & \\
\hline \multicolumn{5}{|l|}{ Marital Status } \\
\hline Unmarried & $20(60.6)$ & $13(39.4)$ & 1 & .014 \\
\hline Married & $69(82.1)$ & $15(17.9)$ & $\begin{array}{l}2.99 \\
(1.22-7.31)\end{array}$ & \\
\hline \multicolumn{5}{|c|}{ Type of Adsorbents used before Earthquake } \\
\hline Disposable Pads & $21(53.8)$ & $18(46.2)$ & 1 & .000 \\
\hline Reusable Cloth & $68(87.2)$ & $10(12.8)$ & $\begin{array}{l}5.82 \\
(2.33-14.55)\end{array}$ & \\
\hline
\end{tabular}

"I used disposable pads before, but I had to make do with my mother's old cotton saree cloth, which came handy." (25-29 years; university graduate; respondent ID 2)

\section{Personal hygiene related issues}

One woman reported that her menstrual period started in the evening after the earthquake. She could not tell her mother or other friends, as she felt that everyone was stressed and overwhelmed by the chaos surrounding the earthquake. She mentioned that:

"I started to bleed on the same day... Only late at night, I was able to approach my mother. We managed to make a napkin from an old cotton saree. I only wore my napkin the following morning. There was no soap to take bath and I had to change before the sun came out." (20-24 years; no schooling; respondent ID 4)

\section{Finding safe space during the first menstrual period}

Apart from the lack of adsorbents, privacy was highlighted as a serious issue. As an issue not openly discussed in society and pertaining just to women, respondents felt that only women would be able to relate to the suffering they had to endure as a result of the lack of resources and privacy:

"I used reusable cloth before as well, so managing a cloth was easy. I found it quite difficult to locate a safe place where I could have some privacy even 
if it is was just for a few minutes. There were people everywhere." (20-24 years; educated up to 8th grade; respondent ID 3)

One of the respondents further elaborated on the lack of safe spaces with adequate privacy:

"I used an old cloth during my menstrual periods. My neighbor found me a secluded area behind the trees where I was told that other women also changed their pads/cloth. I was horrified at the small pile of sanitary cloth disposed openly just a little distance away."

(35-39 years; no schooling; respondent ID 5)

Field notes corresponded with the qualitative expression of the disposal of used pads. There was no designated space for waste disposal and used pads were disposed in open space nearby the place where women and girls went to change the pads.

\section{Discussion}

This mixed methods study highlights the experiences of women and young girls related to menstrual hygiene management in the aftermath of the recent earthquake in Nepal. Although menstrual hygiene management needs are only specific to a subgroup of the population, they appear as an immediate pressing requisite for the women affected and as such, they should be seen as another core need even in post-disaster scenarios. The quantitate findings reveal that $\mathrm{MHM}$ as a priority that was not immediately addressed, however women and girls also list MHM material as less pressing compared to other general needs in immediate post-earthquake situation. The qualitative data presents evidence that for the menstruating women, it indeed was a challenge in timely accessing the material as well as availability of private space for the MHM activities. Our study reiterates the importance of MHM activities for women and adolescent girls and highlights the necessity to design culturally appropriate and sustainable interventions embedded within well-planned interventions in disaster relief efforts to support women and young girls.

Our findings indicate that whilst MHM activities are felt as important priorities for women and girls, they are often overlooked during disasters. Ensuring access to an essential amount of water available for personal use, provision of ready-made hygienic kits containing essential medicines, first aid and sanitary pads, and ensuring women's safety and dignity in using toilets and wash areas are fundamental rights of every woman during disasters and must therefore be safeguarded.

While further participatory research methods could enrich the existing evidence-base, particularly around personal preferences and socio-cultural aspects of menstrual hygiene management, our use of in-depth interviews illuminated the findings from the quantitative data and facilitated its understanding.

In this study, most respondents did not receive any menstrual hygiene adsorbents in the relief materials during the first month post-earthquake. Hence, women had to improvise by making reusable sanitary towels from sarees or cloths, or obtain through their own networks of friends and relatives. While this seems to be the only option during emergencies, these adsorbents might not be hygienic and could potentially lead to infections $[3,18]$. Only half of the respondents in this study received soaps as relief material in the first month following earthquake. Availability of a safe, private space for changing was not available for more than half of the respondents. Safe disposal of sanitary pads was also a concerning issue, echoing the findings reported among displaced girls and women in Myanmar and Lebanon, where some women disposed of used pads together with household waste in dark colored plastic bags [35]. Women and girls in India also report disposal of used sanitary pads in inappropriate places [16].

Our finding on the use of reusable sanitary towels is in concordance with practices reported by others in rural areas of Nepal [12]. In immediate post-disaster situations, most women and girls who menstruate during such events may perceive MHM activities as an immediate, peremptory need. Our findings corroborate with news reports from Nepal $[27,36]$ and from literature which indicate that menstrual hygiene management is often not prioritized in relief works [22]. Such low attention could also point to societal taboos and inadequate sensitivity on MHM within the wider society $[9,19,37]$. Research from elsewhere also supports that menstrual hygiene being exclusively a feminine need is lesser priority in humanitarian responses whereas, the food and security needs expressed by participants are the fundamental immediate needs for everyone [24]. The underlying reasons for the lack of adsorbents within standard relief materials supplied to earthquake victims and survivors on the first month would require further research among the humanitarian workers, logisticians and agencies.

Immediate measures during disasters are considered possible using locally available cloth as adsorbents [13]. The efforts need to emphasize the need for private spaces for women focusing on menstrual hygiene management apart from the toilets. Availability of a toilet still leaves an unmet need for addressing the women's need for menstruation related privacy [38]. Safe disposal of sanitary pads is also essential [39]. The menstruating girl not being able to discuss the need for materials to manage her periods expressed in this study is an example of how silent the women and girls are about menstruation and related 
matters. The inability of women to freely talk about menstruation within their communities suggests that there are still taboos associated with menstruation [40]. In the south Asian context especially in India and Nepal, menstruation comes with many social restrictions including for religious rituals $[9,12,38]$.

Lessons from Myanmar and Lebanon suggests that, women and girls' choice of adsorbents in emergency settings depend on the availability of the materials, privacy for changing the pads and availability of private space for washing and drying the reusable towels or disposing of pads [35]. Most respondents in our study referred using reusable instead of disposable sanitary pads, as these were unavailable despite being more convenient, a predicament also reported by authors in other settings [35]. Reusable sanitary towels seem to be more easily available, and are perhaps a sustainable and culturally suitable alternative in the Nepalese context.

The current study has certain limitations. It was conducted in one earthquake-affected district of Nepal and may not therefore be generalizable to all other areas of Nepal. As our study setting was predominantly rural, our findings may be particularly unsuitable to urban areas of the country. Further, we specifically asked questions related to the first menstrual period management after the earthquake, and as the study was conducted 3 months after the earthquake potential recall bias cannot be overlooked.

\section{Conclusion}

The study brings evidence that MHM activities are lesser prioritized in immediate relief works. As menstruation comes along with cultural and religious taboo, the MHM needs is present as a silent need, which is addressed by the use of local materials and resources in immediate postdisaster situations. The choice of materials for adsorbents is made based on the availability of materials and the privacy for MHM activities While disposable pads are considered more convenient and hygienic, the use of culturally appropriate, local materials and gender sensitive methods of reusable sanitary towels could be considered by relief workers as sustainable and environmental friendly method.

\section{Abbreviations}

MHM: Menstrual hygiene management

\section{Acknowledgements}

We acknowledge the support from BPKIHS, participants of the study and the community people to conduct this study.

\section{Funding}

None declared. ECS is affiliated with the National Institute for Health Research (NIHR) Health Protection Research Unit (HPRU) in Healthcare Associated Infection and Antimicrobial Resistance at Imperial College London in partnership with Public Health England (PHE), and the NIHR Imperial Patient Safety Translational Research Centre. ECS has received an Early Career Research Fellowship from the Antimicrobial Research Collaborative at Imperial College London and acknowledges the support of the Florence Nightingale Foundation. The views expressed are those of the authors and not necessarily those of the NHS, the $\mathrm{NIHR}$, the Department of Health, or Public Health England.

\section{Availability of data and materials}

All data generated or analysed during this study are included in this published article.

\section{Authors' contributions}

SSB has contributed in conceptualisation, designing, collecting data, analysing data, interpretation of data, writing and revising drafts of this manuscript. MB has contributed in designing the study, analysing and interpretation of data, and writing the revised draft of the manuscript. ECS has provided input in the study design, contributed to analysis and interpretation of data, writing and revising of the draft of the manuscript. RBR is involved in study designing, data collection and revision of the manuscript draft. RAS has contributed in designing the study, data analysis, interpretation of data and writing the draft manuscript. PR has contributed in designing the study and revision of the draft of the manuscript. GS has provided input in design, methodology of the study, interpretation of the data and revising the drafts of this manuscript. All authors have approved the final manuscript and agreed to be accountable for all aspects of the work.

\section{Ethics approval and consent to participate}

The Ethical approval for this research was obtained from the Institutional Review Committee of B P Koirala Institute of Health Sciences (Ref: IRC/634/015), Dharan, Nepal. Written informed consent was obtained from each participant before the study. For minors, an assent was taken from the participants along with the consent of a parent/guardian to participate in the study.

\section{Consent for publication}

Not applicable.

\section{Competing interests}

The authors declare that they have no competing interests.

\section{Publisher's Note}

Springer Nature remains neutral with regard to jurisdictional claims in published maps and institutional affiliations.

\section{Author details}

${ }^{1}$ School of Public Health \& Community Medicine, B P Koirala Institute of Health Sciences, Dharan, Nepal. ${ }^{2}$ NIHR Health Protection Research Unit in Healthcare Associated Infection and Antimicrobial Resistance at Imperial College London, London, UK. ${ }^{3}$ Patan Academy of Health Sciences, Kathmandu, Nepal. ${ }^{4}$ Freelance Researcher, Kathmandu, Nepal. ${ }^{5}$ Department of Infectious Disease Epidemiology and Maternal, Adolescent, Reproductive and Child health (MARCH) Centre, London School of Hygiene and Tropical Medicine, London, UK.

Received: 5 January 2017 Accepted: 29 January 2018

Published online: 02 February 2018

\section{References}

1. Biran A, Curtis V, Gautam OP, Greenland K, Islam MS, Schmidt W-P, et al. Menstrual Hygiene. In: Background paper on measuring WASH and food hygiene practices-definition of goals to be tackled post 2015 by the joint monitoring Programme. 1st ed. London: London School of Hygiene and Tropical Medicine; 2012. p. 81.

2. Sahin M. Tackling the stigma and gender marginalization related to menstruation via WASH in schools programmes. Waterlines. 2015;34(1):3-6.

3. Sumpter C, Torondel B. A systematic review of the health and social effects of menstrual hygiene management. PLoS One. 2013;8(4):e62004.

4. McMahon SA, Winch PJ, Caruso BA, Obure AF, Ogutu EA, Ochari IA, et al. "The girl with her period is the one to hang her head" reflections on menstrual management among schoolgirls in rural Kenya. BMC Int Health Hum Rights. 2011;11(1):7.

5. Arumugam B, Nagalingam S, Varman PM, Ravi P, Ganesan R. Menstrual hygiene practices: is it practically impractical ? Intern J Med Public Heal. 2014;4(4):472-6. 
6. Ten VTA. Menstrual hygiene: a neglected condition for the achievement of seven millennium development goals. Zotermeer: Europe External Policy Advisors; 2007. p. 1-24.

7. Bharadwaj S, Patkar A. Menstrual hygiene and Management in Developing Countries: taking stock. Mumbai: Junction Social; 2004.

8. Kaur K, Arora B, Singh GK, Neki NS. Social beliefs and practices associated with menstrual hygiene among adolescent girls of Amritsar, Punjab. India J Int Med Sci Acad. 2012;25(2):69-70.

9. Ranabhat C, Kim C-B, Choi EH, Aryal A, Park MB, Doh YA. Chhaupad culture and reproductive health of women in Nepal. Asia-Pacific J Public Heal. 2015;27(7):785-95.

10. Sebastian A, Hoffmann V, Adelman S. Menstrual management in lowincome countries: needs and trends. Waterlines. 2013;32(2):135-53.

11. Saeed T, Naghma S. Menstrual knowledge and practices of female adolescents in urban Karachi, Pakistan. J Adolesc. 2010:33(4):531-41.

12. Sapkota D, Sharma D, Budhathoki SS, Khanal VK, Pokharel HP. Knowledge and practices regarding menstruation among school going adolescents of rural Nepal. J Kathmandu Med Coll. 2013;2(3):117-21.

13. Budhathoki SS, Bhattachan M, Pokharel PK, Bhadra M, van Teijlingen E. Reusable sanitary towels: promoting menstrual hygiene in post-earthquake Nepal. J Fam Plan Reprod Heal Care. 2017:43:157-9.

14. Alam M-U, Luby SP, Halder AK, Islam K, Opel A, Shoab AK, et al. Menstrual hygiene management among Bangladeshi adolescent schoolgirls and risk factors affecting school absence: results from a cross-sectional survey. BMJ Open. 2017:7(7):e015508.

15. Khanna A, Goyal RS, Bhawsar R. Menstrual practices and reproductive problems: a study of adolescent girls in Rajasthan. J Health Manag. 2005;7:91-107.

16. van Eijk AM, Sivakami M, Thakkar MB, Bauman A, Laserson KF, Coates S, et al. Menstrual hygiene management among adolescent girls in India : a systematic review and meta-analysis. BMJ Open. 2016;6:e010290.

17. Davidson A. Narratives of menstrual product consumption: convenience, culture, or commoditization? Bull Sci Technol Soc. 2012;32(1):56

18. Das P, Baker KK, Dutta A, Swain T, Sahoo S, Das BS, et al. Menstrual hygiene practices, WASH access and the risk of urogenital infection in women from Odisha. India PLoS One. 2015;10(6):1-16.

19. Sommer M, Caruso BA, Sahin M, Calderon T, Cavill S, Mahon T, et al. A time for global action: addressing girls' menstrual hygiene management needs in schools. PLoS Med. 2016;13(2):e1001962.

20. Gupta S, Sinha A. Awareness about reproduction and adolescent changes among school girls of different socioeconomic status. J Obstet Gynecol. 2006;4(56):324-8

21. Adhikari P, Kadel B, Dhungel S, Mandak A. Knowledge and practice regarding menstrual hygiene in rural adolescent girls of Nepal. Kathmandu Univ Med J. 2007:5(19):382-6.

22. Sommer M. Menstrual hygiene Management in Humanitarian Emergencies: gaps and recommendations. Waterlines. 2012;31(1\&2):83-104.

23. Anwar J, Mpofu E, Matthews LR, Shadoul AF, Brock KE. Reproductive health and access to healthcare facilities: risk factors for depression and anxiety in women with an earthquake experience. BMC Public Health. 2011;11:523.

24. Travers $\mathrm{CL}$. No one cares we're bleedling: the place of menstrual management in humanitarian response [dissertation]. Uppsala: Uppsala Universitet; 2015.

25. Budhathoki SS, Gelband H. Manmade earthquake: the hidden health effects of a blockade-induced fuel crisis in Nepal. BMJ Glob Heal. 2016;1(2):e000116.

26. UN Office for the Coordination of Humanitarian Affairs, UN Resident and Humanitarian Coordinator for Nepal. Nepal: Earthquake 2015 Situation Report No.20 (as of 3 June 2015) [Internet]. Reliefweb. 2015 [cited 2015 Oct 7]. Available from: http://reliefweb.int/report/nepal/nepal-earthquake-2015situation-report-no20-3-june-2015

27. Lee B. Nepal Earthquake : Push For Immediate Relief Leaves Menstrual Hygiene Behind [Internet]. International Business Times. 2015 [cited 2015 May 8]. Available from: http://www.ibtimes.com/nepal-earthquake-pushimmediate-relief-leaves-menstrual-hygiene-behind-1905601

28. Krishnan S, Twigg J. Menstrual hygiene: a "silent" need during disaster recovery. Waterlines. 2016:35(3):265-76.

29. Alam K, Rahman MH. Women in natural disasters: a case study from southern coastal region of Bangladesh. Int J Disaster Risk Reduct. 2014;8:68-82.

30. Bradshaw S, Fordham M. Women, girls and disasters: a review for DFID. 2013.

31. Auemaneekul N, Bhandari S, Kerdmongkol P. Menstrual hygiene practices among adolescents in a Rural District of Nepal. Asia J Public Heal. 2013;4:8-15.
32. UNOCHA. Nepal: Sindhupalchok District Road Network Map - 21 September 2015 [Internet]. reliefweb. 2015 [cited 2015 Sep 22]. p. 1. Available from: http://reliefweb.int/map/nepal/nepal-sindhupalchok-district-road-networkmap-21-september-2015

33. Vaismoradi $\mathrm{M}$, Turunen $\mathrm{H}$, Bondas $\mathrm{T}$. Content analysis and thematic analysis implications for conducting a qualitative descriptive study. Nurs Health Sci. 2013;15:398-405.

34. Tol WA, MJD J. Cultural challenges to psychosocial Counselling in Nepal. Transcult psychiatry. 2005:42(2):317-33.

35. Schmitt ML, Clatworthy D, Ratnayake R, Klaesener-Metzner N, Roesch E, Wheeler $\mathrm{E}_{\text {, et }}$ al. Understanding the menstrual hygiene management challenges facing displaced girls and women: findings from qualitative assessments in Myanmar and Lebanon. Confl Health. 2017;11:19.

36. Thacker $P$. After earthquake in Nepal, sanitary menstruation practice at risk [internet]. New York Times. 2015 [cited 2015 May 15]. Available from: http:// nytlive.nytimes.com/womenintheworld/2015/05/01/after-earthquake-innepal-sanitary-menstruation-practices-at-risk/

37. Sommer M, Kjellen M, Pensulo C. Girls' and women's unmet needs for menstrual hygiene management (MHM): the interactions between MHM and sanitation systems in low-income countries. J Water Sanit Hyg Dev. 2013;3(3):283-97.

38. Caruso BA, Clasen TF, Hadley C, Yount KM, Haardörfer R, Rout M, et al, Understanding and defining sanitation insecurity: women's gendered experiences of urination, defecation and menstruation in rural Odisha. India BMJ Glob Heal. 2017;2(4):e000414.

39. Jamieson S. Stinking 10,000 tonne pile of rubbish in great heck. The Telegraph: Yorkshire investigated by Environment Agency; 2015.

40. Sommer M, Phillips-Howard PA, Mahon T, Zients S, Jones M, Caruso BA. Beyond menstrual hygiene: addressing vaginal bleeding throughout the life course in low and middle-income countries. BMJ Glob Heal. 2017; 2(2):e000405.

\section{Submit your next manuscript to BioMed Central and we will help you at every step:}

- We accept pre-submission inquiries

- Our selector tool helps you to find the most relevant journal

- We provide round the clock customer support

- Convenient online submission

- Thorough peer review

- Inclusion in PubMed and all major indexing services

- Maximum visibility for your research

Submit your manuscript at www.biomedcentral.com/submit
) Biomed Central 